\title{
Maternal risk factors for term low birth weight neonates: a retrospective hospital based study at Guntur district, Andhra Pradesh
}

\author{
Soujanya $\mathrm{M}^{1}$, Sravanthi $\mathrm{NL}^{2}$, Vijayalakshmi $\mathrm{B}^{3}$, Kantakumari ${ }^{4}$ \\ ${ }^{1}$ Dr. Maddala Soujanya, Assistant Professor NRI Medical College, ${ }^{2}$ Dr. Nalluru Lakshmi Sravanthi, Assistant Professor, \\ NRI Medical College, ${ }^{3}$ Dr.Vijayalakshmi, Professor, NRI Medical College, ${ }^{4}$ Dr. Kanta Kumari, Assistant Professor, NRI \\ Medical College, Chinakakani, Mangalagiri, Guntur, Andhra Pradesh 522503.
}

Address for Correspondence: Dr. Nalluru Lakshmi Sravanthi, glsravanthi@gmail.com

\begin{abstract}
Introduction: The incidence, morbidity, mortality of low birth weight babies can be reduced if the maternal risk factors are detected early and managed by simple techniques. Materials and Methods: A retrospective analysis of term babies with low birth weight were studied over a period of 1 year using hospital records with emphasis on age, parity, height, BMI and maternal diseases. Results: A total of 121 babies were included. The average birth weight in women aged 1520 years was $1.89 \mathrm{~kg}, 21-30$ years it was $2.2 \mathrm{~kg}$, more than 30 years, it was $2.12 \mathrm{~kg}$, and difference in weight of babies born to mothers aged 15-20 years was statistically lower. The average birth weight among Gravida1 (G1) mothers was $1.95 \mathrm{~kg}$. Among G2 mothers, it was $2.27 \mathrm{~kg}$ and G3 was $2.28 \mathrm{~kg}$. Difference in weights of babies of G1 mothers was significantly lower than babies born to $\mathrm{G} 2$ mothers ( $<<0.0001$ ). The weight of babies of mothers with height $<145 \mathrm{~cm}$ was $2.04 \mathrm{~kg}$, between $145-155 \mathrm{~cm}$ was $2.12 \mathrm{~kg},>155 \mathrm{~cm}$ was $2.13 \mathrm{~kg}$. The weight of babies of mothers with hemoglobin 7-10 $\mathrm{gm} / \mathrm{dl}$ (1.88) was lower than weight of babies of mothers with hemoglobin $>10 \mathrm{gm} / \mathrm{dl}(2.25)$. This was highly significant statistically ( $\mathrm{p}$ value $<0.0001$ ). The weight of babies of mothers with $\mathrm{BMI}<25$ was $2.08 \mathrm{~kg}$, with BMI $20-25 \mathrm{was} 2.12 \mathrm{~kg}$, BMI $>30$ was $2.15 \mathrm{~kg}$, this was not statistically significant. Conclusion: We hereby conclude that lesser age, primiparity and anemia are associated with low birth weight in term infants.
\end{abstract}

Key words: Anaemia, Low birth weight, maternal age, maternal risk factors, Parity, IUGR.

\section{Introduction}

About $16 \%$ of infants in developing countries (more than 19 million) are born weighing less than $2500 \mathrm{gm}$ [1]. It is more than double the level in developed countries, $7 \%$ [2]. The incidence of Low birth weight in India is $21.5 \%$. In Andhra Pradesh, it is $19.4 \%$ [3]. Higher incidence of Low birth weight babies in our country is accounted for by a higher number of babies with intrauterine growth restriction rather than the preterm babies. Infants with intrauterine growth restriction have greater morbidity and mortality than do appropriately grown, gestation matched infants [4]. Low birth weight is a major determinant of malnutrition during infancy because over $40 \%$ of Low birth weight babies are malnourished at 1yr of age [5]. Low birth weight infants have 2.3 times increased risk of mortality due to infections compared to normal birth weight

Manuscript received: $2^{\text {nd }}$ May 2016

Reviewed: $11^{\text {th }}$ May 2016

Author Corrected; $25^{\text {th }}$ May 2016

Accepted for Publication: $12^{\text {th }}$ June 2016 babies after controlling the confounding variables. It is also a significant determinant of infant and childhood morbidity, particularly of neurodevelopmental impairments such as mental retardation and learning disabilities [6]. It is also known to increase the risk of adult onset diseases like Type 2 Diabetes mellitus, Ischemic heart disease and hypertension; this is known as the Barkers hypothesis proposed by British epidemiologist David Barker in 1939. [7].

There are numerous factors contributing to Low birth weight, both maternal and fetal. Among the factors that were identified by Kramer as possible determinants of LBW, maternal factors, socioeconomic status, calorie intake, urinary tract infection and quality of Antenatal checkups were listed as prominent factors [8]. Weight at birth is directly influenced by general level of health status of mother. Infact, maternal environment is the most important determinant of birth weight and factors 
that prevent normal circulation across the placenta cause poor nutrient and oxygen supply to the fetus, restricting the growth. The maternal risk factors are socially and biologically interrelated. The mortality of Low birth weight babies can be reduced if the maternal risk factors are detected early and managed by simple techniques. Thus it is necessary to identify factors prevailing in a particular area responsible for low birth weight. With this background in mind, an attempt has been made to examine the impact of various socioeconomic and demographic maternal characteristics affecting the birth weight of the babies.

\section{Materials and Methods}

A retrospective study was conducted at NRI general hospital using previous hospital records. Permission from college ethical committee was taken. All term (3741 weeks) babies born with low birth weight (weight $<2500$ grams) were included. Study period was 1 year from January 2015 to January 2016.

\section{Inclusion Criteria}

1. All live babies born at term- gestational age assessment was done using ballards score.

2. Singleton pregnancy

\section{Exclusion criteria}

1. Pre-term babies.

2. Post-term babies.

3. Intra-uterine deaths.

4. Still-births.

5. Multiple pregnancy

6. Newborns with congenital malformations

A predesigned proforma was chosen and information was taken. It included the age, parity, Last menstrual period (LMP), Expected delivery date (EDD); Obstetric history of the mother especially information about previous births and abortions; Systemic diseases like hypertension, diabetes mellitus, hypothyroidism etc; results of blood investigations; body mass index and height.

Hemoglobin, done within 15 days prior to delivery was recorded. This was again divided into three categories based on WHO classification for anemia during pregnancy. Hemoglobin $(\mathrm{Hb})$ between 10 and 10.9 gm/dl was considered mild; 7 to 10 as moderate and less than 7 as severe. Birth weight was measured within $1 \mathrm{hr}$ of birth with an electronic weighing machine. Data was then analysed using Excel 2007.

\section{Results}

A total of 3205 babies were born. Among them 510 were of low birth weight. Thus the incidence of LBW was $15.91 \%$. Among these 510, 389 were premature. So, they were excluded from the study.

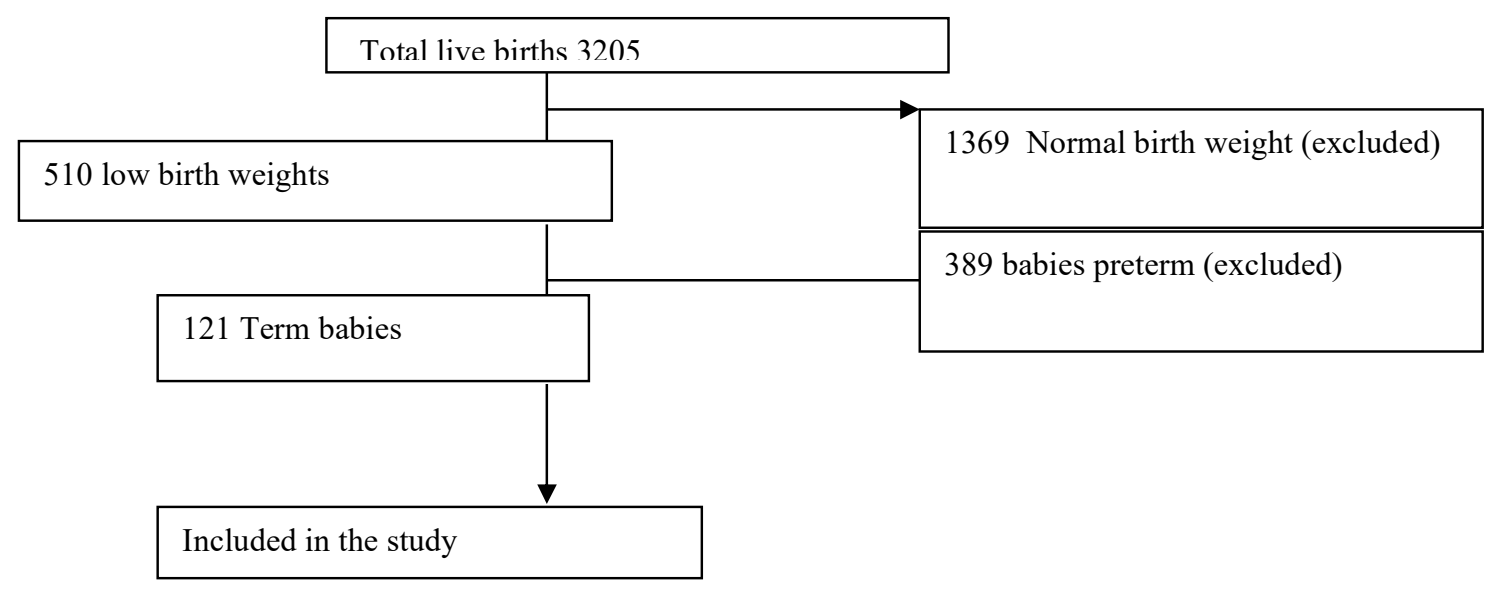

The average birth weight among term low birth weight was found to be $2.11 \mathrm{~kg}$. The lowest recorded birth weight among term babies was $1 \mathrm{~kg}$, one baby weighed $<1.5 \mathrm{~kg}, 53$ weighed between 1.5 and $2 \mathrm{~kg}(43.8 \%)$ and 67 babies weighed between 2 and $2.5 \mathrm{~kg}(55.37 \%)$.

Age and birth weight: Maternal age ranged from 16 yrs to 35 yrs. Maternal age was further classified into 3 age groups. The average birth weight in women between $15-20$ years was $1.89 \mathrm{~kg}$. Between 21 and 30 years it was $2.2 \mathrm{~kg}$ and in 
women aged more than 30 years, it was $2.12 \mathrm{~kg}$. Average birth weight was higher in 20-30 years age category. Majority of the babies fell in to the maternal category of 21 to $30 \mathrm{yrs}$.

Table-1: Average birth weight of babies in different maternal age group categories.

\begin{tabular}{|c|c|c|c|c|}
\hline & Number & Avg. Birth Weight & S.D. & P value \\
\hline $15-20$ yr (group 1) & $50(41.32 \%)$ & $1.89 \mathrm{~kg}$ & 0.339 & group1,2,P $<0.0001$ \\
\hline $21-29 y r($ group 2) & $67(55.37 \%)$ & $2.2 \mathrm{~kg}$ & 0.151 & group2,3.P=0.61 \\
\hline$>30 \mathrm{yr}$ (group 3) & $4(3.3 \%)$ & $2.12 \mathrm{~kg}$ & 0.3 & group $1,3 . \mathrm{P}=0.14$ \\
\hline
\end{tabular}

From, the above table, it is seen that the weight of babies born to $15-20$ years mothers was $1.89 \mathrm{~kg}+0.339$, which was significantly lower $(p<0.0001)$ than weight of babies born to mothers between 21-29 years $(2.2+0.15)$. The mean weight of babies born to mothers aged $>30$ years $(2.12+0.3)$ was higher than mean weight of babies born to mothers aged $15-20$ years, but this was not significant statistically $(\mathrm{p}=0.14)$. There was no significant difference between weights of babies born to mothers aged 21-30 years and $>30$ years.

In Babies, $\leq 1.5 \mathrm{~kg}$ : One baby was born to mother 15-20 year. Babies 1.5-2 kg: 39 mothers in this category were less than $20 \mathrm{yrs}, 13$ between 21 and 29, and 1 was aged more than $30 \mathrm{yrs}$.

Babies 2-2.5 kg: 10 babies of this category were born to women less than 20 yrs, 54 of babies of this category were born to mothers aged between 21 and 29 yrs, the remaining 3 babies were born to mothers $>30$ years.

The proportion of women in 21-30 yrs age group increased as the birth weight increased from $1.5(24.5 \%)$ to greater than $2 \mathrm{~kg}(80.59 \%)$.

Parity and birth weight: The average birth weight among Gravida1 (G1) mothers was $1.956 \mathrm{~kg}$. Among G2 mothers, it was $2.27 \mathrm{~kg}$ and G3 was $2.28 \mathrm{~kg}$. $53.71 \%(65)$ of the LBW babies were born to G1 mothers.

Table 2: Average birth weight of babies in mothers according to parity.

\begin{tabular}{|c|c|c|c|c|}
\hline Gravida & Number & Avg. Birth Weight & S.D. & P value \\
\hline G1 & $65(53.71 \%)$ & $1.95 \mathrm{~kg}$ & 0.3 & G1, G2.P $<0.0001$ \\
\hline G2 & $37(30.57 \%)$ & $2.27 \mathrm{~kg}$ & 0.16 & $\mathrm{G} 2, \mathrm{G} 3 . \mathrm{P}=0.77$ \\
\hline $\mathrm{G} 3$ & $19(15.7 \%)$ & $2.28 \mathrm{~kg}$ & 0.10 & $\mathrm{G} 1, \mathrm{G} 3 . \mathrm{P}<0.0001$ \\
\hline
\end{tabular}

There was a significant difference in weight of babies born to G1 mothers as compared to G2 mothers (p value $<0.0001$ ). There was no significant difference in weight of babies born to G2 and G3 mothers or G1,G3 mothers.

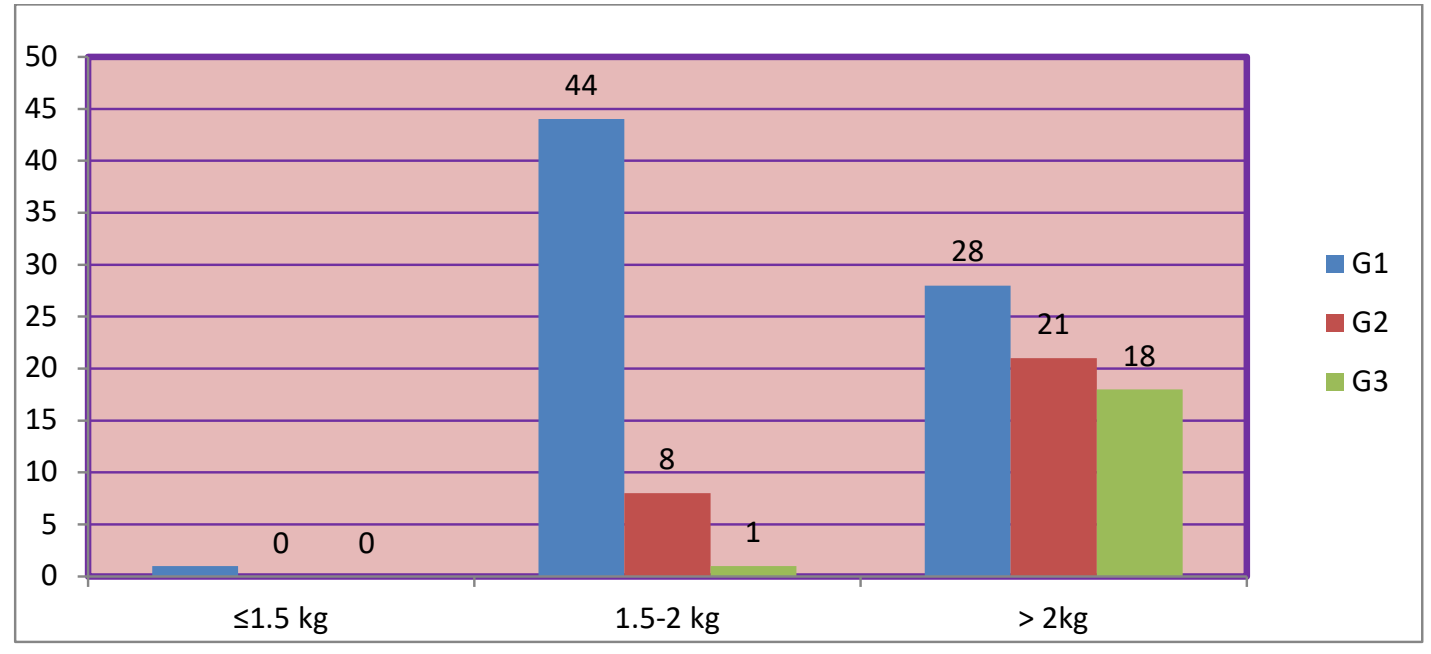

Figure-1: Distribution of the parity of the mother in different baby weight groups 
In babies, $\leq 1.5 \mathrm{~kg}$ : One baby was born to a $\mathrm{G} 1$ mother.

Babies 1.5-2 kg: $84.6 \%$ (44) were born to G1, $15.38 \%$ (8) to G2 and $1.92 \%$ (1) to G3 mothers.

Babies >2 kg: $41.79 \%$ (28) were born to G1, 31.34\% (21) to G2 and $26.86 \%$ (18) to G3 mothers.

In each weight group, G1 mothers were greater than any other group.

Height and birth weight: The heights of the mother ranged from $132 \mathrm{~cm}$ to $151 \mathrm{~cm}$. Mother's height were further divided into 3 categories. In mothers with height below $145 \mathrm{~cm}$, the average birth weight was $2.04 \mathrm{~kg}$. The average birth weight in women measuring between 145 and $155 \mathrm{~cm}$ was $2.12 \mathrm{~kg}$ and in women who were taller than $155 \mathrm{~cm}$, it was $2.13 \mathrm{~kg}$.

Table-3: Average birth weight of babies in different maternal height categories.

\begin{tabular}{|c|c|c|c|c|}
\hline Height & Number & Avg. Birth Weight & S.D & P value \\
\hline$\leq 145 \mathrm{~cm}$ (group 1) & $39(32.23 \%)$ & $2.04 \mathrm{~kg}$ & 0.26 & Group $1,2 . \mathrm{P}=0.16$ \\
\hline $145-155 \mathrm{~cm}$ (group ) & $64(52.89 \%)$ & $2.12 \mathrm{~kg}$ & 0.32 & Group 2,3.P=0.86 \\
\hline$>155 \mathrm{~cm}$ (group 3) & $18(14.87 \%)$ & $2.13 \mathrm{~kg}$ & 0.195 & Group $1,3 . . \mathrm{P}=.14$ \\
\hline
\end{tabular}

In babies $\leq 1.5 \mathrm{~kg}: 100 \%$ (1) were less than $145 \mathrm{~cm}$.

1.5-2 kg: Mothers of 39.62\% (21) babies were less than $145 \mathrm{~cm}, 45.28 \%$ (24) were between 145 and $155 \mathrm{~cm}$, and $15.09 \%$ (8) were taller than $155 \mathrm{~cm}$.

$>2 \mathrm{~kg}$ : 59.7\% (40) were between 145 and $155 \mathrm{~cm}, 25.37 \%$ (17) were less than $145 \mathrm{~cm}$ and $14.9 \%$ (10) were taller than $155 \mathrm{~cm}$. There was no statistically significant difference in babies of mothers of all 3 categories.

Body mass index and birth weight: Body mass index of mothers ranged from as low as 16.7 to a value of 44 . Based on the recommendations of WHO, mothers were further divided into three categories.

Table-4: Average birth weight in mothers of different body mass index groups.

\begin{tabular}{|c|c|c|c|c|}
\hline Body Mass Index & Number & Avg. Birth Weight & S.D. & P value \\
\hline$<20($ group 1) & $16(13.22 \%)$ & $2.08 \mathrm{~kg}$ & 0.20 & Group $1,2 . \mathrm{p}=0.6$ \\
\hline $21-25($ group 2) & $61(50.41 \%)$ & $2.12 \mathrm{~kg}$ & 0.21 & Group2,3 $\mathrm{P}=0.28$ \\
\hline$>25($ group 3) & $44(36.36 \%)$ & $2.15 \mathrm{~kg}$ & 0.17 & Group1,3.P=0.21 \\
\hline
\end{tabular}

The weight of babies of all 3 categories though were increasing from $\mathrm{BMI}<25$ (2.08), to BMI 20-25(2.12), BMI $>30(2.15)$, this was not statistically significant.

Maternal diseases and birth weight: Out of 121 babies, mothers of 31 (25.61\%) babies had a history of some medical problem during pregnancy. The distribution of different diseases encountered in our study is as follows

Table-5: Distriution of various diseases in pregnancy.

\begin{tabular}{|c|c|c|}
\hline Maternal disease & Number & \% \\
\hline Bronchial asthma & 1 & 3.2 \\
\hline Congenital heart disease & 1 & 6.4 \\
\hline Diabetes mellitus & 2 & 6.4 \\
\hline Deep vein thrombosis & 1 & 6.4 \\
\hline Epilepsy & 2 & 6.4 \\
\hline Fever & 2 & 3.2 \\
\hline HbSAg positive & 1 & 3.2 \\
\hline Hypertension & 1 & 3.2 \\
\hline Hyperthyroid & 1 & 41.6 \\
\hline Hypothyroid & 13 & 3.2 \\
\hline Oligohydramnios & 1 & 3.2 \\
\hline Post tuberculosis bronchiectasis & 1 & 12.8 \\
\hline Urinary tract infection & 4 & \\
\hline
\end{tabular}


The mean weight of babies born to mothers with disease was $2.11+0.236$ mean weight of babies born to normal mothers was $2.15+0.17$. This difference was not statistically significant. $(\mathrm{p}=0.3)$

Hemoglobin and birth weight: The lowest recorded $\mathrm{Hb} \%$ was $7.5 \mathrm{gm} / \mathrm{dl}$ while the highest was $18 \mathrm{gm} / \mathrm{dl} .71 .9 \%$ (87) of the mothers had anemia. According to WHO criteria, mothers were divided into 3 categories and compared. 50.41\% (61) mothers fell into the category of moderate anemia (hemoglobin 7-10), while $21.48 \%$ (26) mothers had mild anemia. The average birth weight among mothers with no anemia (hemoglobin>11) was $2.26 \mathrm{~kg}$, with moderate anemia was $1.95 \mathrm{~kg}$ and mild anemia was $2.22 \mathrm{~kg}$. The birth weight increased from $1.95 \mathrm{~kg}$ to $2.26 \mathrm{~kg}$ as the severity of anemia decreased from moderate to no anaemia.

Table 6: Average birth weight according to the severity of anemia.

\begin{tabular}{|c|c|c|c|c|}
\hline Hb. of mothers & Number & Avg. Birth Weight & S.D. & P value \\
\hline $\begin{array}{c}\text { 7-10 gm/dl } \\
\text { Moderate anemia } \\
\text { (group 1) }\end{array}$ & $61(50.41 \%)$ & 1.95 & 0.19 & Group 1,2 \\
\hline $\begin{array}{c}\text { 10-11 gm/dl }<0.0001 \\
\text { Mild anemia } \\
\text { (group 2) }\end{array}$ & $26(21.48 \%)$ & 2.22 & 0.08 & Group 2,3 \\
\hline $\begin{array}{c}>11 \\
\text { Normal } \\
\text { group 3) }\end{array}$ & $33(27.27 \%)$ & 2.26 & 0.12 & Group 1,3 \\
\hline
\end{tabular}

The weight of babies of mothers with hemoglobin 7-10(1.88) was lower than weight of babies of mothers with hemoglobin 10-11(2.22). This was highly significant statistically with a p value $<0.0001$. Similarly the mean weight of babies of mothers with hemoglobin 7-10 (1.88) was significantly lower than mean weight of babies of mothers with hemoglobin $>11(\mathrm{p}<0.0001)$. There was no significant difference in mean weights of babies born to mothers with hemoglobin 10-11, and mothers with hemoglobin $>11$.

In babies, $\leq 1.5 \mathrm{~kg}: 100 \%$ had moderate anemia.

1.5-2 kg: 94.33\% (50) had moderate anemia, 5.6\% (3) had no anemia. $>2 \mathrm{~kg}: 14.92 \%$ (10) of women had moderate anemia, $32.83 \%$ (22) had mild anemia and 52.2\% (35) had no anemia.

The percentage of moderate anemia decreased from $94.33 \%$ to $14.92 \%$ as the birth weight increased as we move from $1.5-2 \mathrm{~kg}$ category to $>2 \mathrm{~kg}$ category.

Sex and birth weight: Girls outnumbered boys by a significant margin. Girls accounted for 67 (55.37\%) while the remaining 54 (44.62) \% were boys.

\section{Discussion}

The etiology of Low birth weight is multifactorial. The present study was therefore undertaken to know the influence of various maternal and social factors on the birth weight of babies. The incidence of Low birth weight was found to be $15.91 \%$. Lower than the National average of $21.5 \%$ and Andhra Pradesh state average of $19.4 \%$.

Maternal age: Mother's were divided into three groups as $<20,21-30$ and 30 years and above. $55.37 \%$ mothers fell in the $21-30$ yrs category and only $40.49 \%$ in the $<20$ yrs category. The mean weight of babies born to mothers aged $>30$ years $(2.12+0.3)$ was higher than mean weight of babies born to15-20 years, but this was not significant statistically. $(\mathrm{p}=0.14)$. There was no significant difference between weights of babies born to 21-30 years and $>30$ years. This is consistent with the study by Ganesh Kumar [9] which showed mother's age less than 20 yrs as a significant determinant of low birth weight. The same has been proved in studies by Dhall $\mathrm{K}$ et al [10], Nair NS et al [11] and Mann Li et al [12]. Deshpande et al, Malvankar et al and Anand and Garg have found no association between age and birth weight $[13,14,15]$

Parity: Mother's were divided into four categories based their parity as G1, G2, G3. There were four G4 and one G6 mother (both were included in G3 
category). $53.71 \%$ of the mothers were primis. The average birth weight among G1 mothers was $1.95 \mathrm{~kg}$ and among G3 was $2.28 \mathrm{~kg}$. When maternal age was assessed in all the three different baby weight groups, G1 mothers were dominant in all of them, $84.6 \%$ in 1.5 $2 \mathrm{~kg}$ group and $41.79 \%$ in $>2 \mathrm{~kg}$ group. There was a significant difference in weight of babies born to G1 mothers as compared to $\mathrm{G} 2$ mothers ( $\mathrm{P}$ value $<0.0001$ ). There was no significant difference in weight of babies born to G2 or G3 mothers or G1, G3 mothers. This is consistent with Deshmukh et al [16], Nurul A et al [17] and Deshpande [13] did not find any effect of parity on birth weight.

Maternal height: Maternal height was further divided into three categories as less than or equal to $145 \mathrm{~cm}$, $145-155 \mathrm{~cm}$ and greater than $155 \mathrm{~cm} .52 .89 \%$ mothers were in the $145-155 \mathrm{~cm}$ category. The average birth weight in mothers shorter than $145 \mathrm{~cm}$ was $2.04 \mathrm{~kg}$ and in mothers who were between 145 and $155 \mathrm{~cm}$ was 2.12 $\mathrm{kg}$. The proportion of mothers who were $145-155 \mathrm{~cm}$ increased from $28 \%$ among babies who weighed between $1.5-2 \mathrm{~kg}$ to $59.7 \%$ among those who weighed greater than $2 \mathrm{~kg}$; There was no significant difference in weights of all 3 categories. This was different from Malik S et al [18] and Deshmukh et al [16] who demonstrated a decrease in birth weight below $140 \mathrm{cms}$.

Maternal body mass index: Based on body mass index, mothers were divided into three categories, BMI less than 20 and between 20 and 25, more than 25. The average birth weight in women who had BMI than 25 was $2.09 \mathrm{~kg}$, while it was $2.10 \mathrm{~kg}$ in women who had BMI 20-25. The average birth weight in women who had BMI $>25$ was 2.09. there was no significant difference in weights of babies of all three categories. The results were consistent with studies by Shreshtha et al [19].

Maternal diseases: $25.61 \%$ mothers in our study had a medical problem. Hypothyroidism (41.6\%) was the commonest of all followed by urinary tract infection at $12.8 \%$. The proportion of pregnancy induced hypertension, Bronchial Asthma (BA), Heart disease, deep vein thrombosis, Hepatitis B, hyperthyroidism, oligohyromnios and bronchiectasis was $3.2 \%$ each while that of epilepsy, fever and diabetes was $6.4 \%$ each. There was no significant difference in weight of babies of both groups.

Anaemia: The prevalence of anemia was $71.9 \%$. $27.27 \%$ mothers had no anemia. The percentage of severe anemia decreased from $31.2 \%$ to $6.1 \%$ as the birth weight increased as we move from $1.5-2 \mathrm{~kg}$ category to $>2 \mathrm{~kg}$ category. In a study done by Deshpande et al [13] around 42.5\% mothers who delivered Low birth weight babies were found to be anemic. Ganesh kumar et al [9] have found this to be $36 \%$.

Sex: Girls accounted for $55.37 \%$ while boys comprised the remaining $44.62 \%$. Girls were more prone to be of lower birth weight. This is consistent with Kramer's meta-analysis [8].

Conclusion: we conclude that significant effect of maternal age, parity, maternal anemia was seen upon birth weight.

\section{Funding: Nil, Conflict of interest: Nil Permission from IRB: Yes}

\section{References}

1. UNICEF Data: Monitoring the Situation of Children and Women: Current status + progress: Unicef; November 2014.

2. Wardlaw TM, editor. Low birthweight: country, regional and global estimates. UNICEF; 2004.

3. International Institute for Population Sciences .India National Family Health Survey (NFHS-3),2005-06.

4. International Institute for Population Sciences; 2007.

5. Marcdante K,Kleigman RM.Nelson essentials of pediatrics. Elsevier Health Sciences; 2014 Feb 25.

6. Singh M. Care of the Newborn. $7^{\text {th }}$ Edition. Sagar Publications; 2010.

7. Chiarotti F, Castignani AM, Puopolo M, MennitiIppolito F, Minniti DS, Di Paolo A. [Effects of socioenvironmental factors on neurocognitive performance in premature or low-birth weight preschoolers]. Annali dell'Istituto superiore di sanita. 2000 Dec;37(4):553-9.

8. Barker DJ. The developmental origins of adult disease. Journal of the American College of Nutrition. 2004 Dec 1;23 (sup6) :588S-95S.

9. Kramer MS. Determinants of low birth weight: methodological assessment and meta-analysis. Bulletin of the World Health Organization. 1987;65(5):663. 
10. Kumar SG, Kumar HH, Jayaram S, Kotian MS. Determinants of low birth weight: a case control study in a district hospital in Karnataka. The Indian Journal of Pediatrics. 2010 Jan 1;77(1):87-9.

11. Dhall K, Bagga R. Maternal determinants of birth weight of north Indian babies. The Indian Journal of Pediatrics. 1995 May 1;62(3):333-44.

12. Nair NS, Rao RP, Chandrashekar S, Bhat HV. Socio-demographic and maternal determinants of low birth weight: a multivariate approach. The Indian Journal of Pediatrics. 2000 Jan 1;67(1):9-14.

13. Mann LI, Tejani NA, Weiss RR. Antenatal diagnosis and management of the small-for-gestational age fetus. American Journal of Obstetrics \& Gynecology. 1974 Jan 12;120(7):A42.

14. Deshpande Jayant D, Phalke DB, Bangal VB, D Peeyuusha BS. Maternal risk factors for low birth weight neonates: a hospital based casecontrol study in rural area of western maharashtra, India. National Journal of Community Medicine. 2011 Oct;2(3):394-8.
15. Mavalankar DV, Gray RH, Trivedi CR. Risk factors for preterm and term low birthweight in Ahmedabad, India. International journal of epidemiology. 1992 Apr $1 ; 21(2): 263-72$

16. Anand K,Garg BS.A study of factors affecting LBW. Indian journal of community medicine. 2000 Apr:6

17. Deshmukh JS, Motghare DD, Zodpey SP, Wadhva SK. Low birth weight and associated maternal factors in an urban area. Indian pediatrics. 1998 Jan 1;35(1):33-6.

18. Amin N, Abel R, Sampathkumar V. Maternal risk factors associated with low birth weight. The Indian Journal of Pediatrics.1993 Mar1; 60(2):269-274.

19. Malik S, Ghidiyal RG, Udani R, Waingankar P. Maternal biosocial factors affecting low birth weight. The Indian Journal of Pediatrics. 1997 May 1; 64 (3) : 373-7.

20. Shrestha I, Sunuwar L, Bhandary S, Sharma P. Correlation between gestational weight gain and birth weight of the infants. Nepal Medical College journal: NMCJ. 2010 Jun;12(2):106-9.

\section{How to cite this article?}

Soujanya M, Sravanthi NL, Vijayalakshmi B, Kantakumari. Maternal risk factors for term low birth weight neonates: a retrospective hospital based study at Guntur district, Andhra Pradesh. Int J Pediatr Res.2016;3(6):433439.doi:10.17511/ijpr.2016.i06.11. 